\title{
Olhar atento às vulnerabilidades infantis
}

FREITAS, Marcos Cezar de; PRADO, Renata Lopes Costa. 0 professor e as vulnerabilidades infantis. São Paulo: Cortez, 2016, 144 p.

Lisandra Ogg Gomes é professora adjunta da Faculdade de Educação do Departamento de Estudos da Infância da Universidade do Estado do Rio de Janeiro

\section{Contato: lisandraogg@yahoo.com.br}

Muito me instigou o título do livro 0 professor e as vulnerabilidades infantis por trazer à tona a dualidade geracional, cultural e social estabelecida entre adulto e criança. Para aqueles que estudam ou pesquisam a infância e as crianças, o livro apresenta ideias, posições e reflexões para se pensar a relação entre crianças e adultos, entre seres e devires de ordens geracionais distintas, mas contemporâneos no espaço e tempo. Também é uma possibilidade de diferenciar ou mudar o olhar em relação à infância e às crianças, pois é um livro que permite repensar a ordem geracional e as problemáticas sociais apresentadas aos adultos e às crianças nos seus modos de pertencimentos, participações e nas formas de proteção.

Ainda que os autores indiquem que o livro é um debate com docentes, considero ser uma excelente possibilidade de trocar ideias com adultos a respeito das crianças, dos lugares a elas reservados na sociedade e das práticas deles em relação a elas. É, assim, um estudo reflexivo para aqueles que têm crianças ou lidam e interagem com elas de um modo geral. Marcos Cezar de Freitas é professor associado livre-docente do Departamento de Educação da Escola de Filosofia, Letras e Ciências Humanas da Universidade Federal de São Paulo e Renata Lopes Costa Prado é professora adjunta do Instituto de Educação de Angra dos Reis da Universidade Federal Fluminense; ambos estão envolvidos com o projeto interdisciplinar que pesquisa e coleta a produção de etnografias relacionadas às vulnerabilidades infantis, a saber, Plataforma de Saberes Inclusivos. 
Nesse livro eles se dedicam à discussão da vulnerabilidade das crianças e da infância, tratando de modo específico: (a) das crianças enfermas nas salas de um ambulatório de alergia e imunologia, (b) das expectativas de professoras de crianças com deficiência matriculadas nas escolas de Educação Infantil, e (c) da análise da legislação brasileira a respeito das pesquisas que envolvem crianças. Portanto, o livro é composto por três capítulos muito bem articulados e com um referência atual e importante para quem deseja compreender o campo dos estudos da infância, assim como adentrar nessa vasta produção teórica.

Com muita maestria e questionamento instigantes, o texto introdutório coloca em debate o conceito de vulnerável e vulnerabilidade, considerando sujeitos, grupos, contextos, circunstâncias e sentidos conforme os campos de conhecimento. As questões apresentadas têm como propósito levar o leitor a refletir a respeito da vulnerabilidade como problemática conjuntural e estrutural. Uma das questões postas é: "A vulnerabilidade é uma característica da criança? Trata-se de uma palavra-chave para descrever a infância?" (p. 13). Nas análises realizadas pelos autores ficam claras a polissemia, a forte marca negativa e as generalizações vinculadas ao conceito como se fosse inerente a um corpo, a uma condição social ou a uma fase da vida. Mas, mais do isso, "Vulnerabilidade é categoria relacional conjugada às instabilidades do cotidiano que se reinventa sempre [...]" (p. 18). E, como bem apontam, a categorização de pessoas e grupos pode ter uma dupla face, pois, por um lado, influencia e direciona recursos para a proteção de quem está sendo descuidado, por outro lado, pode contribuir para estigmatizar grupos e pessoas restringindo sua autonomia e participação.

Posto isso, o primeiro capítulo, que leva o nome "De crianças cronicamente enfermas", propõe a discussão da dupla vulnerabilidade delas, pois, ao passo que se inserem em uma categoria geracional marcada por faltas, incapacidade e incompetências, elas ainda são moldadas pelas enfermidades que atingem seus corpos "vulneráveis".

As reflexões se inserem a partir de um quadro de situações compartilhadas entre as crianças e suas mães nas salas de um ambulatório de alergia e imunologia enquanto esperam pelo atendimento médico rotineiro antes de iniciar suas atividades sociais cotidianas, entre elas, o comparecimento à escola. Em um esforço etnográfico, os autores recolhem e reconhecem o sentido que a fragilidade dessas crianças 
adquire na tessitura das rotinas. Para compreender e apreender os sentidos dessa vulnerabilidade, os autores participaram do espaço-tempo de crianças e mães, esperando onde elas esperavam, aguardando enquanto elas aguardavam e dialogando com as mães somente quando as crianças eram chamadas para o atendimento. As análises tratam de vidas desprovidas de privacidade, corpos cansados e aflitos que buscam por melhora, ausência completa de homens-pais nesse cuidado, espaços e médicos despersonalizados e histórias de mulheres-mães de crianças doentes incompreendidas por essa diferença. 0 texto aborda também que a lida das mulheres-mães com seus filhos e suas filhas envolve mais do que um cuidado médico de corpos, os quais são quase uma extensão delas, mas também envolve aspectos afetivos, econômicos, protetivos, de gênero e conhecimentos compartilhados com outras mães que ultrapassam as determinações médicas.

A vulnerabilidade também está posta na reflexão sobre a doença e as questões de gênero, as mães indicam as diferenças e ideias nas atitudes, no trato e nas suposições a respeito de corpos de meninos e meninas, que são escondidos e acometidos na sua força, no seu vigor e na sua vaidade. Para poderem enfrentar suas doenças os meninos aprendem que é necessário serem homens e as meninas, que não precisam ter tantos cuidados com um corpo que precisa ser mostrado.

De todo modo, o que fica claro é que, ainda que o cuidado e a proteção dos adultos visem a melhora das crianças, são elas que têm seus corpos invadidos, contidos e medicados, são elas que sofrem os temores da doença, das internações, reprovações médicas e aversões sociais. E desde cedo aprendem que é para cima que se olha - para um médico, uma enfermeira, as mães. Portanto, que lugar a sociedade reserva para as crianças enfermas? 0 que pensam as crianças sobre essa série de cuidados? Quais interações e relações estabelecem com seus pares que igualmente vivem essa rotina?

A escola também é parte do cotidiano dessas crianças, e as mães a vislumbram como uma extensão da casa, mas a realidade é outra e as dificuldades estão postas para todos os envolvidos - crianças, mães e docentes. As mães têm expectativas de que os cuidados com seus filhos e suas filhas continuem para além do espaço doméstico. Cuidado que é indissociável do processo educativo da escola de Educação Infantil (BRASIL, 2010). Porém, quais são as expectativas dos 
docentes em relação à chegada de crianças com deficiências físicas, sensoriais e intelectuais à Educação Infantil? É do que trata o segundo capítulo, "Crianças com deficiências na Educação Infantil: o professor e as instabilidades da inclusão". Segundo os autores, a escolha dessa etapa da educação básica foi proposital e estratégica para evitar as cobranças da escolarização, tão própria do Ensino Fundamental.

Inclusão é o que identifica esse capítulo, e Benveniste (1976) lembra que toda palavra é marcada por significados, domínios, compreensões e subjetividades e, se pensada em relação à Educação Infantil, crianças e professoras, essa palavra abrange uma série de sentidos. Por exemplo, a inclusão da Educação Infantil como primeira etapa da educação básica e a garantia de acesso a toda e qualquer criança a uma instituição pública é uma conquista social e política recente e de grande relevância. Assim como é recente a formação docente, inicial e continuada, específica a respeito da educação das crianças pequenas. Por fim, como bem apontam os autores, mais recente ainda é a inclusão de pessoas com deficiências na educação básica. Diante de tantas especificidades, a palavra inclusão expõe as oscilações e instabilidades do sentido que acompanham as crianças com deficiência, as professoras e a Educação Infantil. Isso está posto pelos autores nos registros feitos das falas das professoras acerca de suas expectativas com a chegada da criança com deficiência e da sua família. São expressivos nessas falas a falta de valorização e infraestrutura - material e pessoal -, o desejo por uma formação específica e acesso aos saberes sobre as deficiências, o direito de aprender e participar dessas crianças, as inseguranças e os esforços pretendidos entre escola e família para o bem-estar das crianças. Como se vê, a fala das professoras mostra de modo claro e direto os conflitos vividos na Educação Infantil, um espaço e tempo das, para e com as crianças, que ainda debate e luta por seu reconhecimento social, político e educacional. Assim, há ainda um longo caminho a percorrer para compreender que as diferenças e identidades são antes de tudo social e culturalmente construídas. Mas, como bem indicam os autores, na escola a doença chega antes do sujeito.

Diante de questões tão importantes apresentadas nesses dois capítulos, é evidente que as mudanças na vida das crianças ocorrem ao passo de transformações no conjunto da sociedade. Se atualmente é possível afirmar que as crianças 
são atores sociais e participantes da sua história e cultura, e que a infância é importante na estrutura da sociedade, isso se deve a novos conhecimento, reflexões, estudos, pesquisas e interações entre os sujeitos de variadas instituições e ordens. Entretanto, é no espaço acadêmico que estão sendo criadas barreiras para a realização da pesquisa com crianças, e é disso que trata o capítulo final, "A pesquisa envolvendo seres humanos à luz dos estudos sociais da infância: leitura crítica da legislação brasileira". Os autores problematizam os aspectos sobre ética nas pesquisas com pessoas nas ciências sociais e humanas, prevista pela Resolução 466/12 do Conselho Nacional de Saúde.

Esse capítulo é um trabalho cuidadoso e apresenta ótimas reflexões, trazendo à tona a problemática que sempre envolveu a pesquisa com criança, ou seja, sua cientificidade - objetividade, fidelidade, confiabilidade, neutralidade e validade.

Inicialmente, os autores esclarecem que nas ciências sociais e humanas as crianças e a infância sempre foram estudadas e pesquisadas, mas como "parte da decoração", tendo suas práticas e falas silenciadas, abafadas ou apartadas, utilizadas como pano de fundo "para colorir a vida adulta". De um modo geral, os estudos em ciências sociais e humanas consideraram aspectos específicos da sociedade incluindo as crianças e a infância, por exemplo, no papel de filho(s) e filha(s), no ofício de aluno(s) e aluna(s), no futuro da comunidade ou na história, mas pouco se interessaram em saber sobre suas opiniões, perspectivas e maneiras de ser. De todo modo, alguns campos, como, a sociologia, antropologia e filosofia, para citar apenas alguns, perceberam essa incoerência e passaram a interrogá-las. A emergência de tais estudos demarcaram novos campos e legitimaram teorias, conceitos e métodos. Como bem posto na análise dos autores, os novos paradigmas no estudo da infância orientaram o desenvolvimento de novas investigações que passaram a considerar a infância como uma construção e uma variável de análise social, buscaram compreender as relações e interações socioculturais das crianças, elas como atores sociais, a etnografia como uma metodologia que permite pesquisas mais próximas delas e a infância enquanto um fenômeno social. Vale ressaltar que esse reconhecimento científico da infância e das crianças está em consonância com políticas e diretrizes internacionais. Ainda assim, essa não é uma posição unilateral e as pesquisas se diferenciam ao considerar as 
crianças como objeto, sujeito, ator social e participante ou copesquisadora, como bem advertido nesse capítulo. De acordo com os autores, essas perspectivas coexistem e são usadas lado a lado nas pesquisas contemporâneas. A questão é que até o início do século XX pesquisar crianças e infância não esbarrava em um cuidado ético, sobretudo as pesquisas da área médica. Em 13 de junho de 2013 entra em vigor a Resolução 466/12 do Conselho Nacional de Saúde, substituindo a anterior $196 / 96$, que passa a reger a ética na pesquisa com seres humanos. Uma das críticas dos pesquisadores à antiga resolução era a não separação entre a regulamentação da ética em pesquisas sociais e em ciências biomédicas. Certamente, estudiosos de ambas as áreas sabem das diferenças de se realizar pesquisa com e em seres humanos. Ainda que atualizada e revista em pontos importantes, a nova resolução avança pouco acerca dos aspectos da sua pretensão de universalidade e da concepção de vulnerabilidade.

De modo muito apurado os autores, fundamentados em Benjamin (2004, pp. 12-13), revelam que "a consumação empírica da eticidade jamais se encontra designada na norma ética - e assim seria superestimá-la acreditar que todo e qualquer mandamento empírico já esteja contido nela". Ademais, a ética na pesquisa com crianças é dada por uma postura do pesquisador que as considera como sujeitos de direitos, mas reconhecendo a alteridade entre eles. Por exemplo, a resolução não trata da qualidade do relacionamento que se estabelece entre pesquisador e participantes, que são singulares e diversos. Ainda que muito bem planejado anteriormente na pesquisa, é na relação com as crianças que são abertas outras possibilidades de investigação - técnicas e procedimentos.

Acerca da vulnerabilidade, sabe-se que as crianças precisam de proteção na sociedade, um direito inegável, mas que não pode significar "exclusão protetora" ou tampouco corresponder apenas a uma assinatura dos seus responsáveis em um documento de consentimento livre e esclarecido. Se as crianças têm o direito de serem protegidas, igualmente têm o direito à participação. Significa reconhecer que em qualquer pesquisa os indivíduos são seres em devires, portanto é também na relação de alteridade com o outro que o saber científico é produzido. Sendo assim, negar o direito de participação das crianças nas pesquisas por considerá-las vulneráveis não ajuda a avançar em direção a relações mais éticas da pesquisa. 
Como se vê, é um livro importante por trazer contribuições e argumentações consistentes a respeito da vulnerabilidade e da inclusão das crianças e da/na infância em diferentes aspectos da vida social. E se apresenta como um diálogo admirável com os adultos, na busca por abrir espaços para as crianças e a infância.

\section{REFERÊNCIAS}

BRASIL. Diretrizes Curriculares Nacionais para a Educação Infantil. Brasília: MEC, SEB, 2009.

BENVENISTE, Émile. Problemas de lingüística geral. São Paulo: Editora Nacional, Editorada Universidade de São Paulo, 1976.

LESSARD-HÉBERT, Michelle et al. Investigação qualitativa: fundamentos e práticas. Lisboa: Instituto Piaget, 1990.

Recebido em: 22/06 2017

Revisto em: 23/06 2017

Aceito em: 27/06 2017

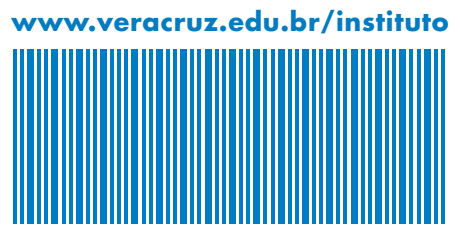

